\title{
Effect of High Pressure Heat Treatment on Hardness and Electrical Conductivity of a Copper-Based Multiple Alloy
}

\author{
Hong $\mathrm{Xu}^{1}$, Yan $\mathrm{Chen}^{2}$ and Jianhua $\mathrm{Liu}^{3 *}$ \\ 1. Institute of Electrical Engineering, Yan Shan University, Qinhuangdao 066004, China \\ 2. Department of Environmental and Chemical Engineering, Yanshan University, Qinhuangdgo 066004, China \\ 3. State Key Laboratory of Metastable Materials Science and Technology, Yanshan University, Qinhuangdao 066004, China
}

\begin{abstract}
A copper-based multiple alloy was treated at different high pressure and $850{ }^{\circ} \mathrm{C}$ for 15 min, and the effect of high pressure heat treatment on the hardness and electrical conductivity of copper-based multiple alloy were studied by electric conductivity instrument and hardness tester. The results show that high pressure heat treatment can increase the hardness and decrease electrical conductivity of the copper-based multiple alloy. After high pressure heat treatment and $500{ }^{\circ} \mathrm{C}$ aging for $2 \mathrm{~h}$, its electrical conductivity can be greatly improved, and the improving is obvious with the pressure increasing.
\end{abstract}

Key words: A copper-based multiple alloy, high pressure heat treatment, hardness, electrical conductivity.

\section{Introduction}

$\mathrm{Cu}$-based alloys have been widely used as conducting wire of integrate circuit, electrode of resistance welding, generator sets and commutator of electric hand tool and so on due to high strength, good electric conductivity [1-3]. With the development of science and technology, based on the premise that the requirement for strength is met, the electrical conductivity is needed to improve as far as possible. Because of the contradiction between strength and conductivity of the copper alloy, generally [4], high-strength is obtained at the expense of conductivity. How to resolve this contradiction is the key issue for copper alloys with high strength and conductivity. In recent years, the research results have shown that high pressure heat treatment can improve the microstructure and properties of $\mathrm{Cu}$-based alloys [5-7]. Therefore, effects of high pressure heat treatment on hardness and electrical conductivity of

*Corresponding author: Jianhua Liu, senior engineer, research field: metallic materials. copper-based multiple alloy were investigated.

\section{Experiment}

The experimental material was an as-cast copper-based multiple alloy, with chemical composition (mass percent, \%) of $96.72 \mathrm{Cu}, 0.37 \mathrm{Cr}$, $0.61 \mathrm{Ag}, 1.27 \mathrm{Se}, 1.03 \mathrm{Te}$. High pressure experiment was carried out on a CS-IIB tester. The samples with dimension of $\Phi 8 \times 10 \mathrm{~mm}^{2}$ were heated up to $850{ }^{\circ} \mathrm{C}$ and held for 15 min under the pressures of 1, 2, 4 and 6 Gpa, respectively. Then the electricity (kept pressure) was shut off and the samples were cooled to room temperature. The specimens before and after high pressure were aging treated at $500{ }^{\circ} \mathrm{C}$ for $2 \mathrm{~h}$ in a SX-4-10 furnace. Hardness and electrical conductivity of the specimens were tested with a THV-5 Vickers hardness tester and a WD-Z type eddy electrical conductivity instrument, respectively. All of the data were taken the average of three measurements. The microstructures were analyzed by Axiovert200MAT metallographic microscope and $\mathrm{S}-3400 \mathrm{~N}$ scanning electron microscope (SEM-BSE). 


\section{Results and Discussion}

\subsection{Microstructure}

Fig. 1 shows microstructures of the copper-based multiple alloy before and after high pressure. It can be seen that the microstructure after $6 \mathrm{Gpa}$ pressure treatment is composed of basis and irregular-shaped particles. Analysis proves that the basis is $\alpha(\mathrm{Cu})$ solid solution and the irregular-shaped particles are $\mathrm{Cu}-\mathrm{Se}$ (Te) compound.

High pressure heat treatment doesn't have a large effect on the microstructural characteristics. The images of SEM-BSE (Fig. 2) indicate that the micropores in the alloy after $6 \mathrm{Gpa}$ pressure treatment are less than in as-cast alloy and the structure is more compact.

\subsection{Influence of High Pressure Heat Treatment on the} Hardness

Fig. 3 shows the hardness of the copper-based multiple alloy under different pressures. The sample of $0 \mathrm{Gpa}$ indicates that it is as-cast. It can be seen that high pressure heat treatment can increase the hardness of copper-based multiple alloy, and the hardness increases with pressure increasing. When the pressures are $1 \mathrm{Gpa}$ and $6 \mathrm{Gpa}$, the values of hardness are $118.54 \mathrm{HV}$ and $127.16 \mathrm{HV}$, respectively, which increase by $26.61 \%$ and $34.75 \%$, respectively, compared with that of as-cast samples (94.37 HV). The reason for it may lie in that the high strain, generated in the specimen at high pressure, leads to the increase in internal dislocation density. This sub-structure can cause the hardening of the alloy. So high pressure heat treatment can increase the hardness of alloy. By aging treatment after high pressure heat treatment, the hardness of copper-based multiple alloy is still higher than that of the as-cast sample by the same aging treatment. The hardness of the sample aging treated at $500{ }^{\circ} \mathrm{C}$ for $2 \mathrm{~h}$ after $6 \mathrm{GPa}$ pressure treatment is $125.03 \mathrm{HV}$, while that of the as-cast sample

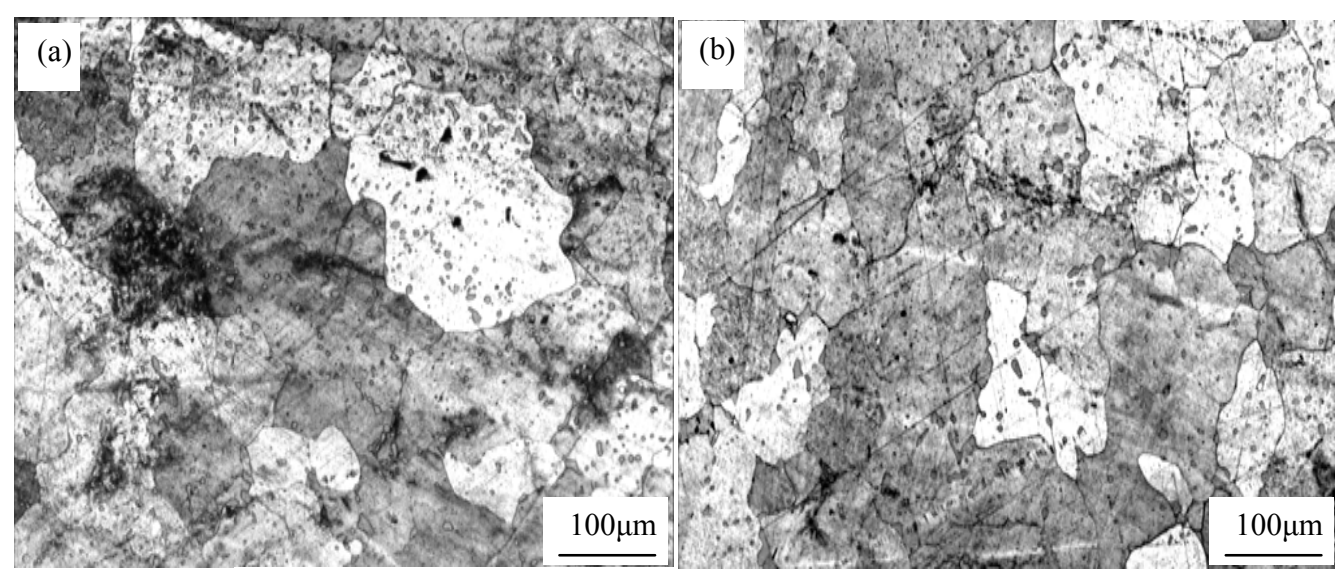

Fig. 1 Microstructures of copper-based multiple alloy: (a) as-cast and (b) 6 GPa treatment.
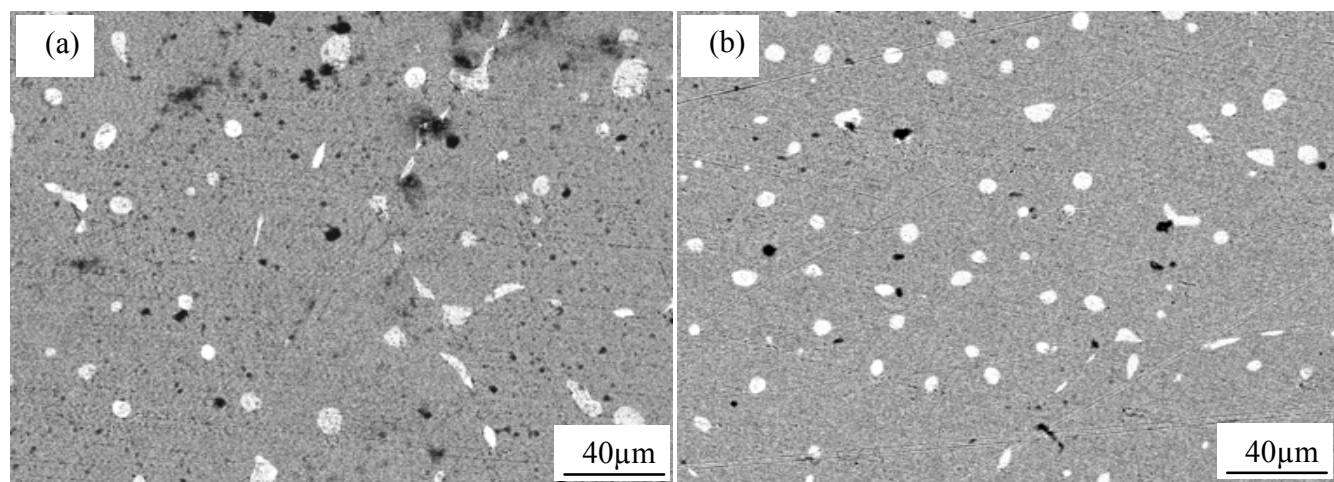

Fig. 2 SEM-BSE images of copper-based multiple alloy: (a) as-cast and (b) 6 GPa treatment. 


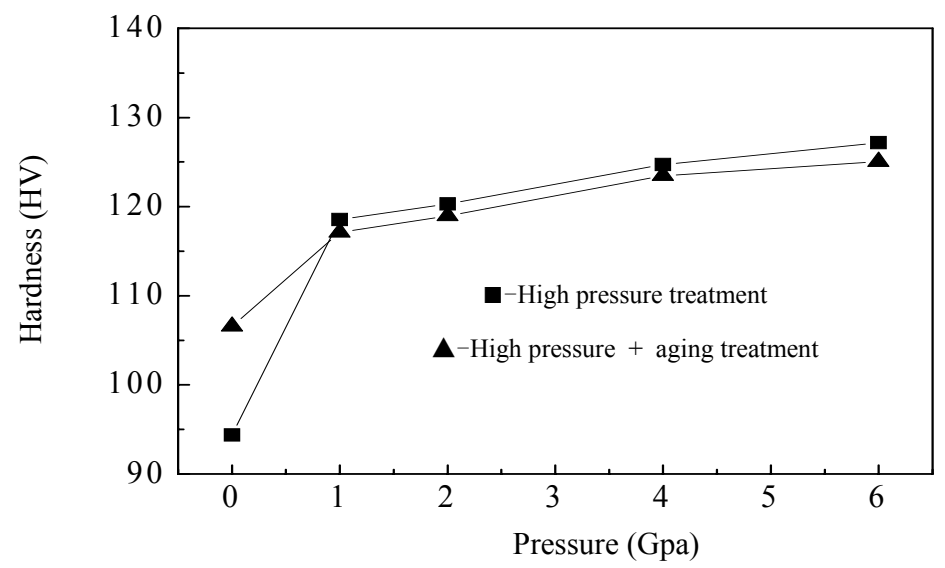

Fig. 3 Effect of pressure on hardness of copper-based multiple alloy.

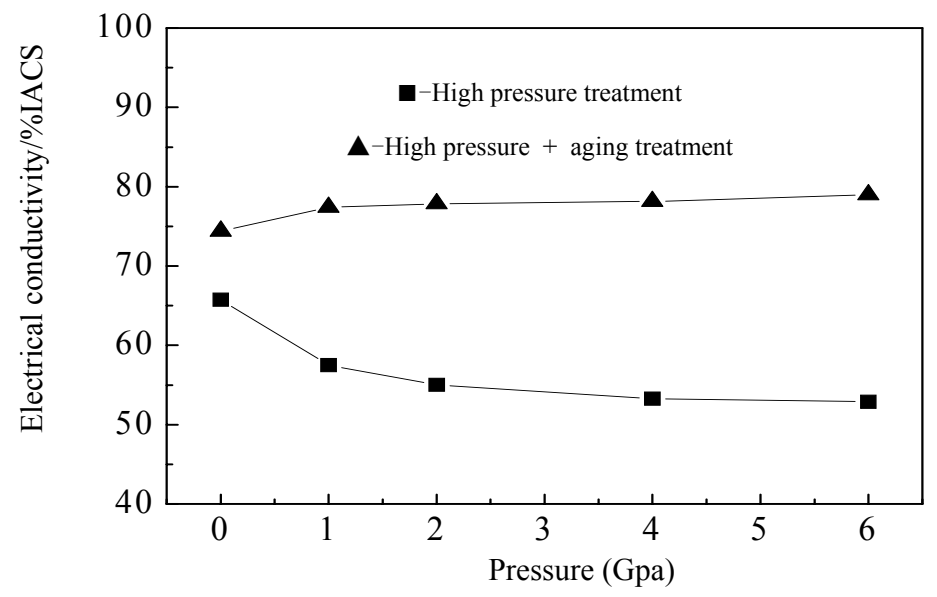

Fig. 4 Effect of pressure on electrical conductivity of copper-based multiple alloy.

subjected to the same aging treatment is $106.55 \mathrm{HV}$. It can also be seen from Fig. 3 that the hardness increases for the as-cast sample after aging treatment, while the hardness decreases for the as-cast sample by aging treatment after high pressure heat treatment, but the decrease is not significant. For example, the hardness difference between before and after aging is $\triangle 2.13 \mathrm{HV}$ for the sample treated under $6 \mathrm{Gpa}$ pressure, which increase by $32.49 \%$, compared with that of as-cast samples. In the aging process of copper-based multiple alloy, the supersaturated solid solution $\mathrm{Cr}$ atoms in the $\mathrm{Cu}$ matrix precipitate in the form of secondary phases, enhancing the effect of aging treatment and increasing the hardness of the alloy [8], and high pressure increases defects, such as a number of dislocation, providing more sites for the segregation and precipitation of solute atoms [9]. These sites make the segregating phase more dispersive, and thus enhance the strengthening effect. Meanwhile, high pressure improves the density of the alloy. As a result, under the same aging treatment condition, the hardness of samples after high pressure heat treatment is higher than that of the as-cast samples. The fact that the hardness decreases for the samples aging treated after high pressure heat treatment may be related to the recovery, reduced lattice distortion and disappearance of dislocation. 


\subsection{Influence of High Pressure Heat Treatment on the Electrical Conductivity}

Fig. 4 shows the electrical conductivity of copper-based multiple alloy under different pressures. It can be seen that high pressure heat treatment can reduce the electrical conductivity of copper-based multiple alloy, and the electrical conductivity decreases with pressure increasing. The electrical conductivity of the samples aging treated at $500{ }^{\circ} \mathrm{C}$ for $2 \mathrm{~h}$ after high pressure heat treatment increases, and the greater the pressure, the higher the electrical conductivity. The electrical conductivity is higher than that of the as-cast samples after the same aging treatment. When the alloy is aging treated at $500{ }^{\circ} \mathrm{C}$ for $2 \mathrm{~h}$ after $6 \mathrm{Gpa}$ pressure treatment, the electrical conductivity is 78.97 IACS, which increases by $20.12 \%$ and $6.12 \%$, respectively, compared with that of as-cast samples (65.74 IACS)and as-cast samples after the same aging treatment (74.41 IACS).

As for the electrical conductivity of $\mathrm{Cu}$-based alloys, it is mainly affected by scattering effect to electrons by solid-solution atoms, vacancies, impurities, distortion, dislocations and grain boundaries $[10,11]$. Lattice distortion caused by high pressure blocks the electron mobility and leads the electron to scatter, resulting in low electrical conductivity. Therefore, the electrical conductivity of copper-based multiple alloys decreases by high pressure heat treatment. In the subsequent aging process, dislocations and other defects, produced by high pressure, offer favorable conditions for the nucleation and growth of precipitation phase, so the precipitation phase segregates more fully. At the same time, crystal defects can be eliminated. Furthermore, the high pressure heat treatment can increase the density of the alloy, reduce the number of microscopic pores of the matrix, and thereby reduce the scattering effect to electrons. The electrical conductivity of the samples after high pressure processing and aging treatment is higher than that of the as-cast samples.

\section{Conclusions}

High pressure heat treatment can increase the hardness and decrease electrical conductivity of the copper-based multiple alloy, and it is obvious with the pressure increasing, and high pressure heat treatment combined with appropriate aging treatment can increase electrical conductivity of the copper-based multiple alloy.

Higher hardness (125.03 HV) and electrical conductivity (78.97 IACS) are obtained when the copper-based multiple alloy is subjected to aging treatment at $500{ }^{\circ} \mathrm{C}$ for $2 \mathrm{~h}$ after $6 \mathrm{Gpa}$ pressure treatment, which increase by $32.49 \%$ and $20.12 \%$, respectively, compared with that of as-cast samples.

\section{Acknowledgements}

This work was supported by the natural science foundation of Hebei Province, China (E2014203135) and Independent research project of YanShan University Young teachers, China (14LGA015).

\section{References}

[1] Sobrero, C. E., Roca, P. La., Roatta, A., Bolmaro, R. E. and Malarría, J. 2012. "Shape Memory Properties of Highly Textured Cu-Al-Ni-(Ti) Alloys." Materials Science and Engineering A 536 (28):207-15.

[2] Akbari-Fakhrabadi, A., Mahmudi, R. Geranmayeh, A. R. and Jamshidijam, M. 2012. "Impression Creep Behavior of a Cu-6Ni-2Mn-2Sn-2Al Alloy." Materials Science and Engineering A 535 (15): 202-8.

[3] Monzen, R., Takagawa, Y., Watanabe, C., Terada, D. and Tsuji, N. 2011. "Mechanical Properties of Precipitation Strengthening Cu-Base Alloys Highly Deformed by ARB Process." Procedia Engineering 10: 2417-22.

[4] Ma, Y. Q. 2013. "Effects of $4 \mathrm{GPa}$ Pressure Heat Treatment on Mechanical Properties and Electrical Conductivity of CuCrNiAl Alloy." Materials Transactions 54 (5): 725-8.

[5] Liu, Y. W., Liu, L. and Zhang, W. 2011. "Effect of High Pressure Heat Treatment on Microstructure and Corrosion Resistance of Brass." Advanced Materials Research 194-196: 1257-60.

[6] Zhao, J., Yin, S., Chen, J. H., Wang, Z., Wen, Q. X. and Yang, Y. M. 2013. "Effects of High Pressure Heat Treatment on Thermal Diffusion Coefficient and Thermal 
Expansion of Cu-50.84Cr-0.48Al Alloy.” Chinese Journal of Rare Metals 37 (5): 834-9.

[7] Wu, L. L., Liu, L. and Liu, J. H. 2012. "Effects of High Pressure Heat Treatment on Microstructure and Micro-Mechanical Properties of Cu77.96Al22.04 Alloy." Matterials Transactions 53 (3): 504-7.

[8] Meng, D. L., Peng, G. R., Liu, J. H. and Zhang, R. J. 2010. "Influence of Heat Treatment on Mechanical Properties of Cu-45Cr-0.56Mo Alloy." Journal of Materials Science and Engineering 4 (9): 72-76.

[9] Zou, G. S., Lu, W., Yue, X. Q., Liu, J. H. and Zhang, R.
J. 2009. "Influence of Deformation and Heat Treatment on Electrical Conductivity of CuMoCr Alloy." Journal of Harbin Institute of Technology 16 (4): 99-102.

[10] Su, J. H., Liu, P. and Dong, Q. M. 2008. “Aging Study of Rapidly Solidified and Solid-Solution Cu-Cr-Sn-Zn Alloy." Journal of Materials Processing Technology 205 (1-3): 366-9.

[11] Song, W., Guo, J. and Liu, J. H. 2007. "Effect of Deformation and Heat Treatment on Properties of CuNiCrAl Alloy." Journal of Materials Science and Engineering 1 (1): 55-60. 